\title{
Correction to: Influence of neighbor competition and tree attributes on the fruit production of Sinomanglietia glauca, an endangered tree species endemic to China
}

\author{
Qing-ni Song $\cdot$ Zhi-yong Xiao $\cdot$ Jia-wen Xu $\cdot$ Shu-ling Song $\cdot$ Feng-gang Luan • \\ Jun Liu • Qing-pei Yang $(\mathbb{B}$
}

Published online: 11 April 2021

(C) Springer Nature B.V. 2021

\section{Correction: Plant Ecol \\ https://doi.org/10.1007/s11258-020-01095-0}

In the original publication of the article, the author's name "Molano-Flores" was published incorrectly in the reference. The correct reference is provided in this correction. Also, the text "Moreover, our results were also consistent with the findings of Molanoflores (2014). He observed that the invasion..." under the heading "Discussion" should read as "Moreover, our results were also consistent with the findings of Molano-Flores (2014). She observed that the invasion...".

\section{Reference}

Molano-Flores B (2014) An invasive plant species decreases native plant reproductive success. Nat Areas J 34(4):465-469

Publisher's Note Springer Nature remains neutral with regard to jurisdictional claims in published maps and institutional affiliations.
The original article can be found online at https:// doi.org/10.1007/s11258-020-01095-0.

Q. Song · J. Xu · S. Song · F. Luan .

J. Liu $\cdot$ Q. Yang $(\square)$

Jiangxi Provincial Key Laboratory for Bamboo, Germplasm Resources and Utilization, Forestry College, Jiangxi Agricultural University, Nanchang 330045, China e-mail: qingpeiyang@126.com

Z. Xiao

Yichun Forestry Institute of Jiangxi, Yichun 336000,

China 